\title{
Elimination of the Vectorial Transmission of Chagas Disease in Central American Countries: Honduras
}

\author{
Carlos Ponce
}

Laboratorio Central de Referencia para Enfermedad de Chagas y Leishmaniasis, Secretaría de Salud de Honduras, Tegucigalpa, Honduras

Key words: Chagas disease - vector - control - Central America

Geographically, Central America is composed by seven countries: Belize, Costa Rica, El Salvador, Guatemala, Honduras, Nicaragua and Panama. The Central American isthmus is located between the Pacific and Atlantic oceans, and unites South America with North America, having a territorial extension of $550,000 \mathrm{~km}^{2}$ and a population of 35 million people. The second country to report human cases of tripanosomiasis americana or Chagas disease was El Salvador (Segovia 1913). In Honduras, the first human case was reported during the decade of the 60 (León-Gómez et al. 1960). Earlier, the natural infection by Trypanosoma cruzi had been reported in Didelphis marsupialis (Robertson 1931). Chagas disease is a priority problem for public health in Central America, specially in El Salvador, Guatemala, Honduras and Nicaragua. The infection prevalence estimated for the population of these four countries is of 7\% (approximately 2 million people). Chronic cardiopathy is the most frequently observed manifestation. In Honduras $20 \%$ of chronic cardiopathies are chagasic and $36 \%$ of pacemakers implanted are for chagasic cardiopaths.

Out of the seven species of triatomines considered of mayor importance for the transmission of T. cruzi to man, three of them: Rhodnius prolixus, Triatoma dimidiata and $R$. pallescens are the main vectors for Central America. R. prolixus is the most efficient, and the one with mayor vectorial action due to its short life cycle, and the high density it reaches inside dwellings. It is found in El Salvador, Guatemala, Honduras and Nicaragua associated strictly with human dwellings, which is different than observed in Venezuela and Colombia were it can be found in wild habitats.

Supported partially by the TDR Programme, WHO/ World Bank/UNDP.

Received 9 June 1999

Accepted 9 August 1999
In Honduras the infestation indexes in areas where this species is prevalent, are less than the infestation indexes of areas where only T. dimidiata exists, but the infection indexes by T. cruzi in the population are higher for areas where transmission occurs by $R$. prolixus than for those by $T$. dimidiata (Ponce et al. 1993).

There is evidence that $R$. prolixus no longer exist in Central America since the past century, but there is for the other species of triatomines. First time it was found, was in El Salvador in 1915. The hipotesis that it could have been introduced to Central America has strengthened the genetic studies of the populations of $R$. prolixus in Honduras and in Colombia, which show that the samples of $R$. prolixus from Honduras represent a subpopulation genetically limited and derived from an original population from South America (Dujardin et al. 1998).

The autochthonous species T. dimidiata is considered the second important vector in Central America. Descriptions made by the Spanish conquerors in several parts of Central Ameica of hematophic insects, coincide with this species, existing in the seven countries, where there is the greater dispersion, and the most wide diversity of domiciliary, peridomiciliary, and wild environments. It also has an urban condition which makes it an important vector in many cities of Central America, and some South American countries were it also exists. The city of Tegucigalpa, capital of Honduras, has topographical, climate, and dwelling conditions, which are favorable for this vector, finding it throughout the city (Ponce \& Zeledón 1973). T. dimidiata is the species responsible for the transmission in Costa Rica, and is the only important species in Belize. R. pallescens is considered the most important species in Panama, and cannot be found in other Central American countries.

Isolated efforts directed towards the control of vectorial transmission, took place until the decade of the 70 in various Central American countries, without continuity to achieve success. As a conse- 
quence of the national prevalence study, carried out in Honduras during 1984, with the support of the World Health Organization and the Pan-American Health Organization, a motivation process for professionals, workers, and health authorities started. It emphasized on the importance of organizing the actions for vectorial transmission control, and for prevention actions. Part of this process was the 1985 study on serological prevalence in blood donors at endemic and nonendemic area hospitals, which revealed a national index of $11.6 \%$ with hospital ranges from 0.5 to $20.2 \%$. This allowed to initiate in Honduras the control of the transfusion transmission, through the serological screening for $T$. cruzi of the blood donors, obtaining the approval of a law making this control procedure mandatory.

The successful experience of the transfusion transmission control done in Honduras has been and is still carried out in other Central American countries with the support of the Pan-American Health Organization. The transfusion transmission control in Central America, has allowed for effective control of the second infection way, strengthening the motivation process is an excellent strategy to justify the political decisions for the control of vectorial transmission.

In 1990, in the Health Secretariat, the National Program for Control and Prevention of Chagas disease, was created. It is dependent on the Vector Transmitted Disease Division, and works coordinately with the Central Reference Laboratory for Chagas Disease. In high endemic areas, control experiences take place, along with operational investigations, clinical studies for disease characterization, epidemiological surveillance, education interventions, and promotion of dwelling improvement. At the same time, and within Resolution XVI from the 1991 Sanitary Conference celebrated in Washington, work is being done to strengthen the political decisions which completed in 1997 with Resolution no. 13 of the XIII Meeting for the Health Sector of Central America celebrated in Belize City, and the launched of the Initiative of the Central American Countries for the Vectorial and Transfusion Transmission Control of Chagas Disease, carried out in Tegucigalpa, Honduras at same year. These achievements are now supported by Resolution WHA 51.14. 51a. World Health Assembly celebrated in Geneva in 1998.

The objectives of the Initiative of the Central American Countries for the Vectorial and Transfusion Transmission Control of Chagas Disease, are: (1) elimination of $R$. prolixus from El Salvador, Guatemala, Honduras and Nicaragua, considering that it is an introduced and strictly domiciliary species; (2) reduction of the infestation and colonization indexes of $T$. dimidiata throughout Central America, considering it being an autuctonous species; (3) strengthening and total coverage of the screening of blood donors for the absolute elimination of transfusion transmission. Success obtained by the initiative of the Southern Cone countries, and the launched of the initiative of the Andean countries in 1997, motivates and warranties the success of the initiative of the Central American countries.

\section{REFERENCES}

Dujardin JP, Muñoz M, Chavez T, Ponce C, Moreno J, Schofield CJ 1998. The origin of Rhodnius prolixus in Central America. Med Vet Entomol 12: 113-115.

León-Gómez A, Flores-Fiallos A, Reyes L, Poujol E, Bonilla M, Gómez C 1960. La enfermedad de Chagas en Honduras. Rev Med Hondureña 28: 78-83.

Ponce C, Zeledón R 1973. La enfermedad de Chagas en Honduras. Bol Of San Panam 75: 239-248.

Ponce C, Ponce E, Flores M, Avila G 1993. Intervention trials of new tools to control transmission of Chagas disease in Honduras. Mem Inst Oswaldo Cruz 88 (Suppl.): 57-58.

Robertson A 1931. Nota sobre un tripanosoma morfológicamente semejante al Trypanosoma cruzi (Chagas 1909), encontrado en una zarigüella Didelphis marsupialis capturada en Tela, Honduras. Rev Med Hondureña 2: 3-13.

Segovia JC 1913. Un caso de tripanosomiasis. Arch Hosp Rosales 8: 249-254. 